\title{
DERECHO A LA VIVIENDA Y DESAHUCIOS: LA PROTECCIÓN DEL DEUDOR HIPOTECARIO EN LA JURISPRUDENCIA DEL TJUE
}

\author{
MANUEL MEDINA GUERRERO \\ Catedrático de Derecho constitucional \\ Universidad de Sevilla
}

SUMARIO

I. Introducción.

II. La situación de partida: procedimiento ejecutivo hipotecario y derecho a la tutela judicial efectiva.

III. La incidencia del derecho europeo sobre protección de los consumidores en la conformación del sistema procesal hipotecario.

IV. La influencia de la Carta de Derechos Fundamentales de la Unión Europea en la protección del deudor hipotecario.

\section{INTRODUCCIÓN}

Probablemente, ninguna consecuencia derivada de la crisis económica ha tenido mayor impacto social y ha marcado más la agenda política en los últimos años que el vertiginoso incremento de los desahucios de viviendas habituales, señaladamente de los resultantes del impago de las hipotecas ${ }^{1}$. Con independencia de la influencia que este problema haya podido tener en la aparición y consolidación de movimientos sociales y nuevas formaciones políticas, es evi-

1 Así, según los datos del Instituto Nacional de Estadística, en el año 2014 el número de ejecuciones hipotecarias sobre viviendas habituales de personas físicas se incrementó un 7’4\%, ascendiendo a un total de 34.680 hogares. Cifra que supuso un $77^{\prime} 6 \%$ del total de ejecuciones hipotecarias de dicho año. 
dente que ha jugado un papel relevante en la actividad normativa del Estado ${ }^{2}$ $\mathrm{y}$, asimismo, de las Comunidades Autónomas en cuanto competentes en materia de vivienda ${ }^{3}$.

No es, sin embargo, la finalidad de este trabajo valorar las medidas normativas adoptadas por su propia iniciativa por los niveles de gobierno estatal y autonómico para mitigar dicho problema, ni consecuentemente nos detendremos a analizar los conflictos que han surgido al respecto ${ }^{4}$. Nuestro objetivo es mucho más limitado: examinar las modificaciones normativas que se han introducido en defensa de los deudores hipotecarios a instancias de la Unión Europea ${ }^{5}$ y, más concretamente, aquellas que han traído causa directamente de decisiones del TJUE ${ }^{6}$.

2 Abundante normativa que ha incidido en diversos planos (procesal, mejora del mercado hipotecario, suspensión de lanzamientos, etc.) y que ha ido intensificando gradualmente la protección del deudor: Real Decreto-Ley 8/2011, de 1 de julio, de medidas de apoyo a los deudores hipotecarios; Real Decreto-Ley 6/2012, de 9 de marzo, de medidas urgentes de protección de deudores hipotecarios sin recursos; Real Decreto-Ley $27 / 2012$, de 15 de noviembre, de medidas urgentes para reforzar la protección de los deudores hipotecarios; Ley 1/2013, de 14 de mayo, de medidas para reforzar la protección a los deudores hipotecarios, reestructuración de deuda y alquiler social; Real Decreto-Ley 1/2015, de 27 de febrero, de mecanismo de segunda oportunidad, reducción de carga financiera y otras medidas de orden social. Sobre al alcance de esta legislación, véase en general Gutiérrez de Cabiedes, P. y Cantero Gamito, M.: «Country Report Spain», en Micklitz, Hans-W. y Domurath, Irina (eds.): Consumer Debt and Social Exclusion in Europe, Ashgate, 2015, p. 67 y ss.

3 Andalucía: Decreto-Ley 6/2013, de 9 de abril, de medidas para asegurar el cumplimiento de la función social de la vivienda y la Ley 4/2013, de 1 de octubre, que lo derogó; Canarias: Ley 2/2014, de 20 de junio, de modificación de la Ley 2/2003, de 30 de enero, de vivienda y de medidas para garantizar el derecho a la vivienda; Cataluña: Ley 20/2014, de 29 de diciembre, de modificación de la Ley 22/2010, de 20 de julio, del Código de Consumo, para la mejora de la protección de las personas consumidoras en materia de créditos y préstamos hipotecarios, vulnerabilidad económica y relaciones de consumo; Navarra: Ley 24/2013, de 2 de julio, de medidas urgentes para garantizar el derecho a la vivienda; País Vasco: Ley 3/2015, de 18 de junio, de vivienda. Así pues, el año 2014 fue particularmente fructífero en lo concerniente a adopción de medidas por parte de las Comunidades Autónomas para mitigar los efectos de los desahucios (véase Informe Comunidades Autónomas 2014, Instituto de Derecho Público, Barcelona, 2015, pp. 18-19).

4 De los recursos de inconstitucionalidad interpuestos por el Presidente del Gobierno contra las normas citadas en la nota 3, la STC 93/2015 ya ha resuelto el relativo al Decreto-Ley andaluz 6/2013, declarando que su disposición adicional segunda invade el ámbito competencial del Estado.

5 Paradójicamente, la apelación a las instituciones europeas se ha utilizado también en detrimento de determinadas medidas autonómicas adoptadas en defensa de aquéllos. Así, la participación de la Comisión y el Banco Central Europeo en documentos e informes que alertaban que dichas medidas podían afectar al buen funcionamiento y la estabilidad del sistema financiero, sirvió como argumento para acordar el mantenimiento de la suspensión de la Ley navarra (ATC 69/2014, FJ 5. ${ }^{\circ}$ ).

6 Soslayaremos, pues, la Directiva 2014/17/UE del Parlamento Europeo y del Consejo, de 4 de febrero de 2014, sobre contratos de crédito celebrados con los consumidores para bienes inmuebles de uso residencial, cuya transposición está fijada, como máximo, para el 21 de mayo de 2016. En cualquier caso, ya los primeros comentarios a la misma valoraron que se había perdido «la ocasión de establecer medidas eficaces que mejoren la situación del consumidor ante las ejecuciones hipotecarias» [AGÜERo OrTIZ, A.: «Directiva 2014/17/UE, de 4 de febrero, sobre contratos de crédito celebrados con los consumidores para bienes inmuebles de uso residencial», publicado el 18 de marzo de 2014, p. 1 (www.uclm.es/centro/cesco)]. 


\section{LA SITUACIÓN DE PARTIDA: PROCEDIMIENTO EJECUTIVO HIPOTECARIO Y DERECHO A LA TUTELA JUDICIAL EFECTIVA}

Antes de que el TJUE tuviera ocasión de pronunciarse sobre la adecuación de nuestro sistema procesal hipotecario al marco jurídico europeo, la constitucionalidad del mismo había sido repetidas veces proclamada por la jurisdicción constitucional. Es más; su examen, desde el punto de vista del derecho a la tutela judicial del deudor, fue abordado frontalmente por el Tribunal Constitucional en una fecha muy temprana, al resolver en la STC 41/1981 sendos recursos de amparo interpuestos por sociedades mercantiles que fueron acumulados y avocados al Pleno. Y, de hecho, la doctrina allí recogida permanecería inmutable hasta nuestros días.

Tras señalar en el FJ $4 .^{\circ}$ que la principal característica del procedimiento de ejecución hipotecaria residía en «la extraordinaria fuerza ejecutiva del título y la paralela disminución de las posibilidades de contenerla mediante la formulación de excepciones», entraría acto seguido a argumentar que tal restricción resultaba consustancial a la propia naturaleza del título que le da sustento:

«En el procedimiento de ejecución hipotecaria, se limita extraordinariamente la contradicción procesal, pero ello no significa que se produzca indefensión. Hay que reconocer, con la doctrina, que en el procedimiento debatido falta la controversia entre las partes. En puridad, es un proceso de ejecución. Más en concreto, es un procedimiento de realización del valor de la finca hipotecada, que carece de una fase de cognición. Tal estructura resulta lógica a partir de la naturaleza del título. (...) El procedimiento es una vía de apremio, en que el juez realiza un derecho del acreedor, que éste no puede realizar por sí sólo porque se lo impide el principio de la paz jurídica. Es lógico que la actividad del juez sea comprobar si subsiste el crédito (si subsiste la sujeción potencial) y si se ha producido la conditio iuris que la hace actual (si se ha incumplido la obligación), de modo que, acreditados registral y judicialmente ambos extremos, se pasa directamente a la enajenación de la finca». (FJ $5 .^{\circ}$ ).

Ahora bien, proseguirá más adelante el TC, el hecho de que el procedimiento de ejecución hipotecaria, en consonancia con la naturaleza del título, carezca de contradicción procesal no supone que el mismo deba reputarse contrario al art. $24 \mathrm{CE}$ por generar indefensión. Y ello sencillamente porque:

«Lo expeditivo de la ejecución no elimina la posibilidad de contradicción que sigue abierta en el juicio ordinario. En rigor, la radical limitación de las excepciones no se refiere a la contradicción considerada en sí misma, sino a su efecto suspensivo sobre la realización del valor: hay una limitación de las excepciones que pueden producir el efecto suspensivo y nada más. (...) No se limitan, pues, las posibilidades de contradecir, sino las de suspender mediante el juego de las excepciones». (FJ 6. ${ }^{\circ}$ ) 
En resumidas cuentas, «la ausencia de fase de cognición conlleva el carácter no definitivo del procedimiento. No se produce el efecto de cosa juzgada y se deja abierta la puerta a un juicio declarativo. Las cuestiones de fondo quedan intactas y pueden discutirse después con toda amplitud» $\left(\mathrm{FJ} 5 .^{\circ}\right)$. «Desde esta perspectiva - concluiría el TC en el FJ 6. - , es claro que no puede haber violación del art. 24 de la Constitución, porque el deudor y el titular del dominio de la finca no quedan indefensos, ni privados de tutela».

Esta argumentación se mantendría invariablemente, como líneas maestras, en la resolución de los diversos recursos de amparo que, de un modo u otro, darían ocasión a que se planteara en los años venideros el mismo tema ${ }^{7}$, y en algunos de los cuales sería la propia vivienda familiar la que estaba en juego. Asegurada plenamente la constitucionalidad del sistema procesal hipotecario, la nueva Ley de Enjuiciamiento Civil (Ley 1/2000, de 7 de enero) se inclinaría por no introducir ningún cambio significativo sobre el particular:

«se mantiene, en lo sustancial, el régimen precedente de la ejecución hipotecaria, caracterizado por la drástica limitación de las causas de oposición del deudor a la ejecución y de los supuestos de suspensión de ésta. El Tribunal Constitucional ha declarado reiteradamente que este régimen no vulnera la Constitución e introducir cambios sustanciales en el mismo podría alterar gravemente el mercado del crédito hipotecario, lo que no parece en absoluto aconsejable» (Exposición de Motivos, XVII).

Pues bien, esta línea jurisprudencial sería corroborada en la más reciente decisión recaída al respecto, a saber, el ATC 113/2011, por el que se inadmitiría una cuestión de inconstitucionalidad que traía causa de un procedimiento de ejecución hipotecaria en el que la parte ejecutada había alegado como motivo de oposición la existencia de cláusulas abusivas. En lo fundamental, el órgano judicial planteaba la posible inconstitucionalidad de la Ley 1/2000, «en cuanto a los motivos tasados de oposición a la ejecución hipotecaria, incluso cuando el bien gravado constituye la vivienda habitual del ejecutado (art. 695 LEC)». Frente a las anteriores resoluciones referidas, este ATC 113/2011 presenta dos aspectos novedosos: además del derecho a la tutela judicial, se alega la vulneración del derecho a la vivienda digna (art. $47 \mathrm{CE}$ ), aspecto soslayado en las anteriores al quedar excluido este derecho de la vía del amparo constitucional; y, por otro lado, se plantea la cuestión en un momento en que ya era claramente perceptible la enorme repercusión de la crisis económica en la proliferación de los desahucios.

En lo concerniente a la posible lesión del derecho a la tutela judicial efectiva, el ATC 113/2011, tras reproducir extensamente la doctrina antes referida con cita de las numerosas resoluciones recaídas al respecto, declararía el carácter notoriamente infundado de la cuestión al considerar que el Tribunal ya había re-

7 SSTC 64/1985, FJ 2; 8/1991, FJ 2; 6/1992, FJ 3; 217/1993, FJ 2; 296/1993, FJ 4; 223/1997, FFJJ 3-5; 158/1997, FFJ 5-7. 
suelto en anteriores Sentencias las dudas planteadas por el órgano judicial. Y el rechazo de la vulneración del derecho a la vivienda no se presentaría sino como conexión o consecuencia de lo anterior (FJ 4..$^{\circ}$. El ATC 113/2011 se limitó, pues, a aplicar en sus exactos términos la consolidada doctrina acuñada a principio de los años ochenta, sin entrar a considerar en modo alguno cómo pudo afectar a la cuestión debatida el muy diferente contexto socioeconómico actual; circunstancia que sería reprochada en el voto particular formulado por Gay Montalvo, pues, según su opinión, debió examinarse la constitucionalidad de los preceptos cuestionados a la luz del nuevo contexto económico y social ${ }^{9}$. Para el Tribunal, sin embargo, la adecuación de dicho régimen procesal a un mercado financiero y a un entorno económico sustancialmente distintos a los existentes treinta años atrás era una tarea que — ajena a la jurisdicción constitucional— debía confiarse exclusivamente al proceso político ${ }^{10}$.

En definitiva, la posición jurisprudencial absolutamente consolidada era que las peculiaridades del procedimiento ejecutivo hipotecario no vulneraban el derecho a la defensa ex art. 24.1 CE, toda vez que quedaba abierta a los interesados la vía del juicio declarativo para la defensa de sus derechos. Cualquier posibilidad de mejora en este ámbito quedaba, pues, a la sola disposición del legislador. Cerrada así la vía constitucional, la tutela de los deudores hipotecarios se abriría paso a través del Derecho de la Unión y, más específicamente, a través de la normativa en materia de protección de los consumidores. Un cauce que sería profusamente utilizado por los órganos judiciales, no sólo para hacer frente a las limitaciones procesales con el resultado que veremos a continuación, sino en general para combatir otras posibles prácticas abusivas que se entendían amparadas o toleradas por la legislación interna ${ }^{11}$.

8 «(...) este Tribunal ya ha despejado las dudas formuladas, declarando la conformidad del régimen procesal cuestionado con el referido derecho fundamental, de cuya hipotética vulneración el órgano proponente hace depender la lesión de otros derechos y principios constitucionales, como la interdicción de la arbitrariedad (art. 9.3 CE) y el derecho a una vivienda digna (art. $47 \mathrm{CE}$ ), que en consecuencia carece de justificación a la luz del examen realizado».

9 Véanse especialmente los puntos 3 y 4 de su voto concurrente. No dejaron de formularse críticas al criterio sustentado en el voto particular, al considerarse que los cambios en la situación económica no justificaban la modificación del juicio de constitucionalidad, sino que debían ser afrontados por el legislador [DOMínguez Luelmo, ANDrÉs: «La STJUE de 14 de marzo de 2013: Dificultades de interpretación y aplicación por los Tribunales», Revista CESCO de Derecho de Consumo n. ${ }^{\circ}$ 5/2013, p. 11 (http://www.revista.uclm.es/index.php/cesco)].

10 «...la cuestión de inconstitucionalidad no es cauce procesal idóneo para que los órganos jurisdiccionales puedan cuestionar de modo genérico o abstracto la constitucionalidad de un régimen o esquema legal... por contraste con un hipotético modelo alternativo, que no le compete formular al órgano proponente ni corresponde valorar a este Tribunal Constitucional por ser materia de la exclusiva competencia del legislador, dentro de cuyos límites constitucionales dispone de un amplio margen de libertad de elección que este Tribunal ni puede ni debe restringir» (FJ 4. ${ }^{\circ}$ in fine).

11 En este extremo, el recurso al TJUE no ha sido tan exitoso, puesto que están excluidas del ámbito de aplicación de la Directiva 93/13/CEE las cláusulas contractuales que reflejen disposiciones legales o reglamentarias (art. 1.2). Así, por citar un ejemplo relevante, han quedado al margen de la revisión del TJUE 


\section{LA INCIDENCIA DEL DERECHO EUROPEO SOBRE PROTECCIÓN DE LOS CONSUMIDORES EN LA CONFORMACIÓN DEL SISTEMA PROCESAL HIPOTECARIO}

\section{La Sentencia Aziz: La reforma de la LEC}

La primera referencia jurisprudencial a tomar en consideración debe ser, sin duda, la Sentencia del Tribunal de Justicia (Sala Primera) de 14 de marzo de 2013, que vino a resolver una petición de decisión prejudicial formulada por el Juzgado de lo Mercantil n. 3 de Barcelona; solicitud que el órgano judicial formuló en el marco de un litigio referente a la validez de determinadas cláusulas de un contrato de préstamo hipotecario concertado entre el Sr. Aziz y Catalunyacaixa. Debe notarse que la controversia se presenta formalmente como un puro caso de Derecho del Consumo, puesto que la petición tiene por objeto la interpretación de la Directiva 93/13/CEE del Consejo, de 5 de abril de 1993, sobre las cláusulas abusivas en los contratos celebrados con consumidores.

Soslayando aquellos aspectos del caso que - aun siendo inequívocamente relevantes - nos apartarían del objetivo de este trabajo ${ }^{12}$, la principal cuestión planteada por el órgano judicial fue la de determinar si el ordenamiento procesal español satisfacía la exigencia prevista en el art. 7, apartado 1, de la Directiva, según el cual: «Los Estados miembros velarán por que, en interés de los consumidores y de los competidores profesionales, existan medios adecuados y eficaces para que cese el uso de cláusulas abusivas en los contratos celebrados entre profesionales y consumidores». Las dudas sobre la adecuación de la normativa española al marco de la Directiva se fundamentaban, esencialmente, en los siguientes aspectos:

1. En el procedimiento de ejecución hipotecaria los motivos de oposición están estrictamente tasados en el art. 695.1 LEC, sin que entre ellos se incluyera la alegación del carácter abusivo de alguna de las cláusulas del contrato de préstamo.

\footnotetext{
cuestiones tales como la posibilidad de que la responsabilidad del deudor alcance a los demás bienes de su patrimonio en el caso de que la subasta del inmueble sea insuficiente para cubrir el crédito, o la posibilidad de que el ejecutante se adjudique el inmueble por un $50 \%$ de su valor de tasación si no comparece ningún licitador a la subasta [Sentencia del Tribunal de Justicia (Sala Sexta) de 30 de abril de 2014 (Barclays Bank)]

12 Como la fijación del concepto «cláusula abusiva» empleado en el art. 3 de la Directiva y la valoración de si tenían tal carácter las que eran objeto del litigio, a saber: la posibilidad de vencimiento anticipado en los contratos de larga duración por incumplimiento del deudor en un periodo limitado y concreto; la cláusula relativa a la fijación de unos intereses de demora que no coincide con los criterios de determinación de los intereses en otros contratos que afectan a consumidores; y, por último, la cláusula referente a la liquidación unilateral por el prestamista del importe de la deuda impagada, vinculada a la posibilidad de iniciar el procedimiento de ejecución hipotecaria. Sobre esta segunda cuestión prejudicial, véanse los párrafos 65-76 de la Sentencia.
} 
2. Por consiguiente, esta pretensión sólo podía hacerse valer en un procedimiento declarativo posterior, que sin embargo no tiene efecto suspensivo de la ejecución hipotecaria (art. 698.1 LEC).

3. En consecuencia, por más que se termine declarando el carácter abusivo de la cláusula, la adjudicación final a un tercero del bien hipotecado presenta casi siempre un carácter irreversible, pues el ordenamiento procesal únicamente contempla como excepción al respecto el supuesto de que el consumidor realice una anotación preventiva de la demanda de nulidad de la hipoteca con anterioridad a la nota marginal de expedición de certificación de cargas (art. 131 LHL).

En la resolución de esta cuestión prejudicial, el TJUE, aun reconociendo las peculiaridades del caso (ap. 49), comenzaría recordando la afirmación vertida en anteriores Sentencias a propósito de la interpretación de la Directiva 93/13, a saber, que «el juez nacional deberá apreciar de oficio el carácter abusivo de una cláusula contractual incluida en el ámbito de aplicación de la Directiva y, de este modo, subsanar el desequilibrio que existe entre el consumidor y el profesional» (ap. 46) ${ }^{13}$. A continuación, el TJUE traería a colación su consolidada doctrina sobre la autonomía procesal de la que deben disponer los Estados miembros para garantizar la salvaguarda de los derechos que el ordenamiento de la Unión reconozca a los ciudadanos; principio de autonomía procesal que el TJUE ha empleado a menudo en el control de las cláusulas abusivas en los contratos con consumidores ${ }^{14}$. Como es sabido, de conformidad con dicha doctrina, a ellos corresponde regular libremente los diversos procedimientos, siempre y cuando se atengan, de una parte, a la condición de que no adopten un régimen más riguroso que el fijado para supuestos semejantes de carácter interno (principio de equivalencia) y, de otro lado, que no hagan imposible en la práctica o excesivamente difícil el ejercicio de los derechos que atribuya a los consumidores la normativa europea (principio de efectividad). Pues bien, a juicio del Tribunal, no podía considerarse vulnerado el principio de equivalencia, habida cuenta de que la imposibilidad de que el juez que conoce el proceso declarativo adopte medidas cautelares no sólo se proyecta a los casos en que se alegue la existencia de cláusulas abusivas, con base en el art. 6 de la Directiva, sino también cuando se sostenga que las cláusulas resultan contrarias a las normas nacionales de orden público (ap. 52).

13 Como recuerda la Sentencia en el apartado 44, la clave de bóveda sobre la que se construye en buena medida la jurisprudencia en la materia es la constatación de que «el sistema de protección que establece la Directiva se basa en la idea de que el consumidor se halla en situación de inferioridad respecto al profesional, en lo referido tanto a la capacidad de negociación como al nivel de información», de tal suerte que, al interpretar la misma, debe tenderse a restaurar el equilibrio entre ambos.

14 Así, el apartado 50 de la Sentencia que nos ocupa se hace eco de las sentencias de 26 de octubre de 2006, Mostaza Claro, apartado 24, y de 6 de octubre de 2009, Asturcom Telecomunicaciones, apartado 38. 
Sin embargo, sería la quiebra del principio de efectividad la que apreciaría el TJUE en el régimen procesal objeto del litigio. En efecto, debe recordarse que, pese a que se termine acordando en el proceso declarativo la nulidad de la cláusula abusiva, la adjudicación final a un tercero del inmueble hipotecado tiene casi siempre un carácter irreversible, pues solo se prevé la reintegración del mismo en el supuesto de que el consumidor efectúe una anotación preventiva de la demanda de nulidad de la hipoteca con anterioridad a la nota marginal de expedición de certificación de cargas (art. 131 LH). Y este supuesto excepcional no resulta suficiente para considerar salvaguardado el principio de efectividad: «habida cuenta del desarrollo y de las peculiaridades del procedimiento de ejecución hipotecaria controvertido en el litigio principal, tal supuesto debe considerarse residual, ya que existe un riesgo no desdeñable de que el consumidor afectado no realice esa anotación preventiva en los plazos fijados para ello, ya sea debido al carácter sumamente rápido del procedimiento de ejecución en cuestión, ya sea porque ignora o no percibe la amplitud de sus derechos» (ap. 58). Así pues, el hecho de que el juez no pueda adoptar medidas cautelares que suspendan o entorpezcan el procedimiento de ejecución hipotecaria, «cuando acordar tales medidas resulte necesario para garantizar la plena eficacia de su decisión final, puede menoscabar la efectividad de la protección que pretende garantizar la Directiva» (ap. 59). Haciendo suya la argumentación ofrecida en sus conclusiones por la Abogada General Kokott, puntualizaría el TJUE que, una vez realizada la ejecución del inmueble hipotecado, la eventual declaración del carácter abusivo de la cláusula y, con ella, de la nulidad del procedimiento de ejecución solo permitiría «garantizar al consumidor una protección a posteriori meramente indemnizatoria, que resulta incompleta e insuficiente y no constituye un medio adecuado y eficaz para que cese el uso de dicha cláusula, en contra de lo que establece el artículo 7, apartado 1, de la Directiva 93/13» (ap. 60).

$\mathrm{Y}$ aunque aparezca como argumento ad abundantiam, no debe infravalorarse la «presencia» que tuvo en la resolución del caso la circunstancia de tratarse de la vivienda familiar: «Así ocurre con mayor razón cuando, como en el litigio principal, el bien que constituye el objeto de la garantía hipotecaria es la vivienda del consumidor perjudicado y de su familia, puesto que el mencionado mecanismo de protección de los consumidores, limitado al pago de una indemnización por daños y perjuicios, no es adecuado para evitar la pérdida definitiva e irreversible de la vivienda» (ap. 61) $)^{15}$.

En conclusión, la Sentencia declararía la incompatibilidad con el derecho europeo del repetido régimen procesal, ya que la respuesta que dio el TJUE a esta cuestión prejudicial fue la siguiente:

15 También en este extremo siguió muy de cerca las conclusiones de la Abogada general Kokott (apartado 52). 
«la Directiva debe interpretarse en el sentido de que se opone a una normativa de un Estado miembro, como la controvertida en el litigio principal, que, al mismo tiempo que no prevé, en el marco del procedimiento de ejecución hipotecaria, la posibilidad de formular motivos de oposición basados en el carácter abusivo de una cláusula contractual que constituye el fundamento del título ejecutivo, no permite que el juez que conozca del proceso declarativo, competente para apreciar el carácter abusivo de esa cláusula, adopte medidas cautelares, entre ellas, en particular, la suspensión del procedimiento de ejecución hipotecaria, cuando acordar tales medidas sea necesario para garantizar la plena eficacia de su decisión final» (apartado 64; el énfasis es nuestro).

Como era por lo demás previsible, la resolución tuvo una inmediata y muy relevante incidencia práctica, toda vez que, fundamentándose inmediatamente en la misma, algunos jueces comenzaron a acordar de oficio la suspensión del procedimiento de ejecución hipotecaria y dar audiencia al ejecutado para que pudiera formular motivos de oposición basados en el carácter abusivo de las cláusulas contractuales $^{16}$. Si a ello se añade las numerosas dudas que suscitaba la aplicación práctica de esta jurisprudencia por los tribunales, se hacía evidente, por elementales razones de seguridad jurídica, que resultaba imprescindible acometer las modificaciones legislativas precisas para acomodar nuestro régimen procesal a la Sentencia Aziz. Y puesto que la contradicción con la Directiva residía en la acción conjunta $^{17}$ del modo en que se configuraba, de una parte, el procedimiento ejecutivo hipotecario (que excluía a las cláusulas abusivas de los motivos de oposición) y, de otro lado, el procedimiento declarativo (que impedía al juez acordar la suspensión de la ejecución), en línea de principio podía considerarse suficiente con operar en cualquiera de ambos aspectos ${ }^{18}$.

La Ley 1/2013, de 14 de mayo, de medidas para reforzar la protección a los deudores hipotecarios, reestructuración de deuda y alquiler social, se inclinaría por introducir las modificaciones pertinentes en el procedimiento ejecutivo para adaptarlo a la jurisprudencia sentada en Aziz. En concreto, y por lo que a nosotros interesa, reforma la LEC para añadir como nueva causa de oposición la existencia de cláusulas abusivas en el título (arts. $557.17 .^{\mathrm{a}}$ y $\left.695.14 .^{\mathrm{a}} \mathrm{LEC}\right)^{19}$; permite que los

16 Domínguez Luelmo, Andrés: «La STJUE de 14 de marzo de 2013: Dificultades de interpretación y aplicación por los Tribunales» cit., p. 14. Pero incluso antes de que el TJUE resolviera el caso, ya se habían adoptado autos de suspensión de forma cautelar (véase Cordero LobATo, E.: «Control judicial sobre cláusulas abusivas y ejecuciones hipotecarias», Revista Aranzadi Doctrinal n. ${ }^{\circ}$ 2/2013).

17 Véase el apartado 64 arriba transcrito.

18 Un sector de la doctrina entendió preferible la segunda opción, puesto que ampliar las causas de oposición podría entrañar una «desnaturalización del procedimiento ejecutivo» (SÁNCHEZ GonZÁLEZ, M. PAZ: «Incidencia del carácter abusivo de una cláusula contractual sobre el procedimiento de ejecución hipotecaria», Revista de Derecho Comunitario Europeo, n. ${ }^{4} 4$, 2013, pp. 338-339).

$19 \mathrm{El}$ art. 695.1.4. ${ }^{\mathrm{a}}$ precisa del siguiente modo esta nueva causa de oposición: «El carácter abusivo de una cláusula contractual que constituya el fundamento de la ejecución o que hubiera determinado la cantidad exigible». La invocación de la misma suspende la ejecución hasta que se resuelva el incidente (art. 695.2 LEC); y, en caso de estimarse la existencia de una cláusula abusiva, «se acordará el sobreseimiento de la ejecución 
jueces controlen de oficio el carácter abusivo de las mismas, al incorporar un nuevo párrafo al art. 552 LEC disponiendo que, cuando el tribunal apreciare que alguna cláusula pudiera ser calificada como abusiva, se dé audiencia por cinco días a las partes; y, en fin, se añadiría un punto tercero al art. 561.1 LEC que dispone que, en caso de declararse dicho carácter, el auto determinaría las consecuencias de esta declaración, decretando bien la improcedencia de la ejecución, bien despachando la misma sin aplicación de la cláusula o cláusulas consideradas abusivas.

Por otra parte, importa notar que su Disposición transitoria cuarta estableció que estas modificaciones de la LEC serían de aplicación a los procesos de ejecución iniciados a su entrada en vigor. Más concretamente, fijaba un plazo preclusivo de un mes para formular oposición con base en cualquiera de las causas contempladas en los arts. 557 y 695 LEC, o bien para iniciar un incidente extraordinario de oposición basado en las nuevas causas del art. 557.1.7. ${ }^{a}$ y 695.1.4. ${ }^{a}$ LEC en el caso de que en el procedimiento ya hubiese transcurrido el plazo de oposición de diez días previsto en el art. 556.1 LEC. El citado plazo preclusivo de un mes se computaría desde el día siguiente a la entrada en vigor de la Ley 1/2013, esto es, el 15 de mayo, fecha de su publicación en el BOE, toda vez que su publicidad «tendrá el carácter de comunicación plena y válida a los efectos de notificación y cómputo de los plazos..., no siendo necesario en ningún caso dictar resolución expresa al efecto» (apartado 4 de la citada Disposición transitoria cuarta).

Pero sobre esta Disposición transitoria tendremos que volver páginas abajo. Ahora lo que procede es apuntar que la adecuación de la Ley 1/2013 para reequilibrar la más débil posición del consumidor, tal y como reclama la reiterada Directiva, sería de inmediato cuestionada por diversos tribunales ante el TJUE ${ }^{20}$.

\section{La reforma de la reforma: La STJUE de 17 de julio de 2014}

El siguiente paso jurisprudencial que tuvo un impacto directo en nuestro sistema procesal hipotecario lo daría la STJUE de 17 de julio de 2014 (Sala Primera), que resolvería la petición de decisión prejudicial planteada por la Audiencia Provincial de Castellón en el marco de un litigio entre los señores Sánchez Morcillo y Abril García y el Banco Bilbao Vizcaya Argentaria. Nuevamente, la principal norma parámetro utilizada para controlar la adecuación de la legislación nacional al derecho europeo fue el art. 7.1 de la Directiva 93/13/CEE, pero, en esta ocasión, el órgano judicial planteó, abierta y expresamente, la posible incompatibilidad de la normativa interna con el derecho a la tutela judicial efec-

cuando la cláusula contractual fundamente la ejecución», y, en cualquier otro caso, se continuará con la ejecución pero dejando de aplicar la cláusula abusiva (art. 695.3 LEC).

20 Además de los casos a los que haremos referencia en el texto, cabe añadir la petición de decisión prejudicial planteada por el Juzgado de Primera Instancia n. 34 de Barcelona (Asunto C-645/13), que sería archivada mediante Auto del Presidente del Tribunal de Justicia de 18 de noviembre de 2014. 
tiva (art. 47 de la Carta de los Derecho Fundamentales de la Unión Europea). A juicio de la Audiencia Provincial de Castellón, cabía dudar de que el art. 695.4 LEC respetase tanto la obligación de que existan medios adecuados y eficaces para evitar el uso de cláusulas abusivas impuesta por la Directiva ${ }^{21}$, como el derecho del art. 47 de la Carta — particularmente, el principio de igualdad de armas-, por cuanto, al regular el recurso contra la resolución que decide la oposición a la ejecución sobre bienes hipotecados, únicamente permite recurrir en apelación el auto que acuerda el sobreseimiento del proceso o la inaplicación de una cláusula abusiva, de tal suerte que la vía del recurso sólo está abierta al ejecutante cuando se estima la oposición del ejecutado, quedando, en consecuencia, vedada al consumidor en el caso de que se rechace su oposición.

Se planteaba así ante el TJUE — para decirlo con los términos empleados por el propio Tribunal - una «problemática inédita en relación con la que dio lugar a la Sentencia Aziz» (ap. 30); entre otras razones porque, durante la sustanciación del litigio principal, entró en vigor la reforma de la LEC acometida en la Ley 1/2013, y de ésta derivaría directamente la controversia: la Ley 1/2013 modifica el art. 695.1 LEC para incluir la nueva causa de oposición al objeto de proteger la posición del deudor hipotecario, pero no se llega a proyectar esa finalidad en la regulación del régimen de recursos, pues, aunque la Ley 1/2013 reforma también el art. 695.4 LEC, mantiene el monopolio del recurso de apelación en manos del ejecutante.

Algunas dudas se suscitaron, sin embargo, acerca de la competencia del TJUE para enjuiciar la adecuación del art. 695.4 LEC a la reiterada Directiva, habida cuenta de que su art. 1.2 establece que no están sometidas a la misma «las cláusulas contractuales que reflejen disposiciones legales o reglamentarias imperativas». Y es que, como argumentó el Abogado general Wahl en sus conclusiones, a la vista de que los demandados en el procedimiento de ejecución se habían limitado a alegar un vicio de forma, podría pensarse que la controversia «no se deriva del contrato de préstamo hipotecario que vincula a las partes en el litigio principal, sino de las disposiciones imperativas de la Ley de enjuiciamiento civil» (ap. 26). No obstante, pese a estas reticencias, sobre la base de que el Tribunal remitente había hecho referencia a la cláusula de interés de demora del $19 \%$ y en atención a la presunción de pertinencia de que gozan las cuestiones (ap. 27), consideraría que no cabía excluir a priori la aplicabilidad de la Directiva al asunto en cuestión. Por lo demás, parece evidente que la asunción de la pertinencia de la cuestión permitiría seguir avanzando en la configuración de la doctrina sentada en Aziz. Y de hecho esta relevancia del asunto sería subrayada por el Abogado general, que comenzaría precisamente sus conclusiones con la afirmación de que el asunto ofrecía al Tribunal de Justicia «la oportunidad de precisar que la in-

21 En el caso en cuestión el carácter abusivo se planteaba respecto de la cláusula que fijaba el interés moratorio en el $19 \%$ anual, en tanto que el tipo de interés legal en España era del $4 \%$ anual en el tiempo en que se produjo el litigio. 
fluencia del Derecho de la Unión en materia de consumidores sobre el Derecho procesal de los Estados miembros no está exenta de límites» (ap. 1), anticipando así la dirección y el sentido de su informe.

En efecto, en opinión de Wahl, no cabía objetar nada a la norma cuestionada desde el punto de vista del principio de equivalencia, ni tampoco podía achacársele la quiebra del principio de efectividad. La efectividad de la protección conferida por la Directiva habría quedado ya satisfecha con las modificaciones introducidas en la LEC, que ahora ya permite que el deudor alegue la existencia de cláusulas abusivas como causa de oposición en el procedimiento ejecutivo hipotecario ${ }^{22}$, que el propio órgano judicial las revise de oficio y que, en su caso, acuerde la suspensión del procedimiento (ap. 41 y 45). A su juicio, pues, los criterios jurisprudenciales acuñados en la Sentencia $A z i z$ se respetaban en el renovado régimen procesal; máxime cuando, de acuerdo con una constante línea jurisprudencial, el derecho fundamental ex art. 47 de la Carta no comprende el derecho a la doble instancia procesal (ap. 42-43) y, en cualquier caso, siempre queda abierta la vía del procedimiento declarativo ordinario (ap. 54).

Por otra parte, tampoco aprecia el Abogado general la pretendida lesión del principio de igualdad de armas que se infiere del segundo apartado del art. $47 \mathrm{de}$ la Carta, puesto que el desequilibrio existente entre el profesional y el consumidor en punto a la capacidad de recurrir deriva de la propia naturaleza del procedimiento de ejecución hipotecaria. Siendo precisamente el objetivo de este procedimiento proteger al titular de un título ejecutivo privilegiado, resulta justificado este «'privilegio" aparente del que disfruta el acreedor» (ap. 63).

El TJUE se apartaría, sin embargo, sustancialmente de la posición del Abogado General ${ }^{23}$. Y la argumentación en torno al art. 47 de la Carta será determinante en la resolución de la petición. Cosa bastante natural porque el principio de efectividad -en cuanto límite o condicionante del principio de autonomía procesal de los Estados, según jurisprudencia consolidada- se proyecta o encarna en dicho derecho fundamental: «(...) la obligación de los Estados miembros de garantizar la efectividad de los derechos que la Directiva 93/13 confiere a los justiciables frente a la aplicación de cláusulas abusivas implica una exigencia de tutela judicial, consagrada asimismo en el artículo 47 de la Carta, que el juez nacional debe observar... Esta tutela judicial ha de extenderse tanto a la designación de los

22 Y aunque la oposición a la ejecución hipotecaria se presentó poco antes de que entrara en vigor la Ley $1 / 2013$, debe recordarse que su Disposición transitoria cuarta permitía formular un incidente extraordinario de oposición basado en la nueva causa relativa a la existencia de cláusulas abusivas.

23 Una dura crítica a la Sentencia hacen Carrasco, A. y LyCZkowska, K.: «STJUE de 17 de julio de 2014, Asunto C-169/14, Banco Bilbao Vizcaya Argentaria. Un nuevo (y esta vez defectuoso) pronunciamiento del TJUE sobre procedimiento hipotecario español», Revista CESCO de Derecho de Consumo, n. ${ }^{\circ}$ 10/2014 (http://www.revista.uclm.es/index.php/cesco). De entrada, y en línea con las dudas mostradas al respecto por el abogado general, entienden que la consulta era impertinente, toda vez que el art. 695.4 LEC no es una cláusula contractual, sino un precepto procesal que, además, «no tiene ningún contenido remotamente relacionado con la Directiva de cláusulas abusivas» (pp. 9-10). 
tribunales competentes para conocer de las demandas basadas en el Derecho de la Unión como a la definición de la regulación procesal de tales demandas» (apartado 35). Y habida cuenta de que el derecho fundamental ex artículo 47 de la Carta no comprende el derecho a la doble instancia judicial (apartado 36), el centro del debate girará en torno al posible quebrantamiento del principio de igualdad de armas: «En efecto, constituye jurisprudencia reiterada del Tribunal de Justicia que el principio de igualdad de armas, lo mismo que, en particular, el de contradicción, no es sino el corolario del concepto mismo de proceso justo, que implica la obligación de ofrecer a cada una de las partes una oportunidad razonable de formular sus pretensiones en condiciones que no la coloquen en una situación de manifiesta desventaja en relación con la parte contraria» (apartado 49).

Consiguientemente, las normas de la Unión que sirven de parámetro interactúan, generan un efecto recíproco, potenciando el art. 47 de la Carta la virtualidad tuitiva de la Directiva. Si «el sistema de protección que establece la Directiva 93/13 se basa en la idea de que el consumidor se halla en situación de inferioridad respecto al profesional» (apartado 22), el principio de igualdad de armas derivado del art. 47 de la Carta no viene sino a extremar el deber de diligencia que pende sobre los legisladores nacionales de lograr que esa situación de «inferioridad» del consumidor se vea neutralizada en el ámbito jurisdiccional.

Pues bien, antes de abordar frontalmente y de forma específica el examen del art. 695.4 LEC desde la perspectiva del principio de igualdad de armas, la Sentencia evalúa la débil posición del deudor en el conjunto del sistema procesal español en materia de ejecución hipotecaria, pese a las modificaciones introducidas tras la reforma de la Ley 1/2013 (apartados 38-43); valoración en la que, siquiera de forma incidental, no deja de reflejarse la relevancia del bien hipotecado objeto del litigio (vivienda familiar) ${ }^{24}$. Una vez hecho esto, y tras recordar que el art. 695.4 LEC impide al consumidor recurrir la decisión desestimatoria de la oposición a la ejecución mientras que sí habilita la vía del recurso al acreedor ejecutante (ap. 44), el TJUE no dudará en reconocer que dicho artículo «coloca al consumidor, en su condición de deudor ejecutado, en una situación de inferioridad en relación con el profesional, en su condición de acreedor ejecutante, en lo que atañe a la tutela judicial de los derechos que puede invocar, al amparo de la Directiva 93/13, frente a la utilización de cláusulas abusivas» (ap. 45). Así pues, proseguirá más adelante el TJUE, el art. 695 LEC «resulta contrario al principio de igualdad de armas o de

24 En este sentido, se señala en el apartado 38: «(...) según las normas procesales españolas, puede ocurrir que un procedimiento de ejecución hipotecaria que tenga por objeto un bien inmueble que responda a una necesidad básica del consumidor, a saber, procurarse una vivienda, sea incoado a instancia de un profesional sobre la base de un documento notarial dotado de fuerza ejecutiva, sin que el contenido de dicho documento ni siquiera haya sido objeto de un examen judicial destinado a determinar el carácter eventualmente abusivo de una o varias de las cláusulas que contenga». Y más adelante: «(...) el sistema procesal español, considerado en su conjunto y tal como resulta aplicable en el litigio principal, expone al consumidor, o incluso a su familia... al riesgo de perder su vivienda como consecuencia de la venta forzosa de ésta...» (apartado 43). 
igualdad procesal», que «forma parte integrante del principio de la tutela judicial efectiva de los derechos que el ordenamiento jurídico de la Unión confiere a los justiciables, tal como se garantiza en el artículo 47 de la Carta» (ap. 48).

En cualquier caso, la inadecuación de la normativa nacional a las exigencias de la normativa europea se predica del concreto artículo 695.4 LEC pero puesto en conexión con el sistema procesal hipotecario en su conjunto ${ }^{25}$. Así se desprende de la declaración del TJUE:

«El artículo 7, apartado 1, de la Directiva 93/13/CEE del Consejo, de 5 de abril de 1993, sobre las cláusulas abusivas en los contratos celebrados con consumidores, en relación con el artículo 47 de la Carta de los Derechos Fundamentales de la Unión Europea, debe interpretarse en el sentido de que se opone a un sistema de procedimientos de ejecución, como el controvertido en el litigio principal, que establece que el procedimiento de ejecución hipotecaria no podrá ser suspendido por el juez que conozca del proceso declarativo, juez que, en su resolución final, podrá acordar a lo sumo una indemnización que compense el perjuicio sufrido por el consumidor, en la medida en que éste, en su condición de deudor ejecutado, no puede recurrir en apelación contra la resolución mediante la que se desestime su oposición a la ejecución, mientras que el profesional, acreedor ejecutante, sí puede interponer recurso de apelación contra la resolución que acuerde el sobreseimiento de la ejecución o declare la inaplicación de la cláusula abusiva».

Un par de observaciones sobre la STJUE de 17 de julio de 2014 antes de pasar al siguiente asunto. La primera: que venía a apuntalar — vía art. 10.2 CEla apreciación sustentada por un sector de la doctrina de que el art. 695.4 LEC - con independencia de su adecuación o no al Derecho de la Unión - adolecía de inconstitucionalidad por lesionar el principio de igualdad de armas ex art. 24 $\mathrm{CE}^{26}$. De hecho, poco antes se había planteado una cuestión de inconstitucionalidad sobre el particular, que, sin embargo, no daría ocasión a que se dictase una resolución sobre el fondo del asunto por parte del Tribunal Constitucional, al considerar que faltaba en el Auto de planteamiento una determinación concluyente del juicio de aplicabilidad y relevancia (ATC 70/2014, de 10 de marzo) ${ }^{27}$.

$25 «(\ldots)$ procede declarar que el sistema procesal controvertido en el litigio principal pone en peligro la realización del objetivo perseguido por la Directiva 93/13. En efecto este desequilibrio entre los medios procesales de que disponen, por un lado, el consumidor y, por otro, el profesional, no hace sino acentuar el desequilibrio que existe entre las partes contratantes...» (ap. 46).

26 En este sentido, Carrasco y LyCZKowska: «(...) el art. 695.4 LEC no es compatible con las exigencias constitucionales españolas. Si, por virtud de la Sentencia Aziz, nos hemos visto obligados a colar en el art. 695 LECiv una nueva causa de oposición, no podemos luego mostrar nuestro descontento con la racanería en materia de recursos. Si el ejecutante (banco) puede apelar, el ejecutado consumidor ha de poder apelar» («STJUE de 17 de julio de $2014 \ldots$... cit., p. 9).

27 Al plantearse la cuestión, aún no se había resuelto la oposición a la ejecución por la parte demandada y el Auto no exteriorizaba si la misma iba a tener un signo desestimatorio, único supuesto en que sería relevante el art. 695.4 $\mathrm{LEC}\left(\mathrm{FFJJ} 3 .^{\circ}-5 .^{\circ}\right)$. 
Y por otro lado, que, lejos de satisfacer la aspiración del Abogado general de que el asunto diera ocasión a fijar los límites de la influencia de la normativa europea sobre protección de los consumidores en la legislación procesal de los Estados miembros, esta resolución supuso un paso más en el proceso de desmantelamiento de nuestro tradicional sistema de ejecución hipotecaria, resultante de la singular relación entre el Derecho europeo de cláusulas abusivas y el Derecho procesal español, sembrando así la incertidumbre acerca de cuál sería el siguiente hito en dicho proceso $^{28}$.

Obviamente, la consecuencia prácticamente inesquivable de esta STJUE era proceder a la modificación del art. 695.4 LEC para permitir el recurso de apelación contra los autos que desestimen la causa de oposición relativa a la existencia de cláusulas abusivas. Y así se haría en la Disposición final tercera del Real Decreto-Ley 11/2014, de 5 de septiembre, de medidas urgentes en materia concur$\mathrm{sal}^{29}$. Por lo demás, su Disposición transitoria cuarta optó por asumir un régimen transitorio parejo al adoptado en la Ley $1 / 2013$, esto es, posibilidad de utilizar el recurso de apelación en aquellos procedimientos de ejecución iniciados a su entrada en vigor que no hubieran culminado con la puesta en posesión del inmueble al adquirente; fijación de un plazo preclusivo de un mes para su interposición a contar desde la entrada en vigor del Real Decreto-Ley, por cuanto se atribuía a su publicidad el carácter de comunicación plena y válida a los efectos de notificación y cómputo de los plazos. Tras la conversión de este Decreto-Ley en la Ley 9/2015, de 25 de mayo, de medidas urgentes en materia concursal, se mantendrían en términos prácticamente idénticos las referidas Disposición final tercera y Disposición transitoria cuarta, con una sola y relevante excepción: la ampliación a dos meses del plazo preclusivo para la interposición del recurso de apelación. Las razones de este cambio se comprenderán mejor tras analizar el siguiente asunto.

\section{3. ¿Es suficiente la reforma del régimen transitorio?: Las conclusiones del Abogado general Maciej Szpunar en el asunto C-8/14}

El asunto C-8/14 versa sobre la petición de decisión prejudicial planteada por el Juzgado de Primera Instancia n. ${ }^{\circ} 4$ de Martorell en relación con la Dispo-

28 Demos la palabra nuevamente a CARRASCO y LyCZKOwsKA: «Queremos suponer que la cosa no irá más adelante que la de la modificación correspondiente del art. 695.4 LECiv... Pero esta Sentencia ha dejado 'tocada' la hipoteca española de una forma que no resultaba necesaria para ser congruente en la resolución de la cuestión prejudicial. Lo malo del caso es que la hipoteca española está ya muy 'tocada' por dedos groseros de todo porte, que verán con buenos ojos el incremento de confusión que ahora se echa encima. Esperemos la próxima cuestión prejudicial y el nuevo parto de los montes» («STJUE de 17 de julio de 2014...» cit., p. 13)

29 La Audiencia Provincial de Castellón, en el mismo litigio, volvería a plantear cuestión prejudicial en relación con el reformado art. 695.4 LEC (asunto C-539/14). El Auto del Tribunal de Justicia (Sala Primera), de 16 de julio de 2015, tras aplicar la doctrina de la STJUE de 17 de julio de 2014, no apreciaría contradicción de dicha disposición con la normativa europea. 
sición transitoria cuarta de la Ley $1 / 2013^{30}$. Más concretamente, las partes demandadas en el litigio presentaron incidente extraordinario de oposición a la ejecución hipotecaria una vez transcurrido el plazo preclusivo de un mes previsto en dicha disposición transitoria para invocar el carácter abusivo de las cláusulas contractuales. Alegaron ante el órgano jurisdiccional que el establecimiento de un plazo preclusivo para alegar la existencia de cláusulas abusivas en el título ejecutivo no resultaba conforme con la Directiva 93/13, y que, en cualquier caso, la fijación del plazo de un mes era excesivamente corto a la vista del elevado número de afectados, lo que impedía a los profesionales jurídicos atender todos los casos que se les planteaban. Mediante auto de 28 de octubre de 2013, el órgano judicial decidió plantear al TJUE la siguiente cuestión prejudicial: «Si el plazo de un mes... debe entenderse que se opone al sentido de los artículos 6 y 7 de la Directiva 93/13/CEE».

En las conclusiones del Abogado general Maciej Szpunar, que se presentaron el 13 de mayo de 2015, se propondría, en efecto, que se declarase la incompatibilidad de la disposición transitoria con la normativa europea. A tal objeto, comenzaría reformulando ${ }^{31}$ la cuestión planteada en los siguientes términos: «... debe entenderse que con la cuestión prejudicial se pretende en esencia dilucidar si, a la luz de los principios de equivalencia y de efectividad, los artículos 6 y 7 de la Directiva 93/13 se oponen a una disposición transitoria nacional, como la controvertida en el litigio principal, que impone a los consumidores un plazo preclusivo de un mes, a partir del día siguiente al de la publicación de la ley de la que forme parte dicha disposición...» (apartado 27).

A juicio del abogado general, si bien nada cabe objetar a la duración del plazo ya que «un mes es suficiente para plantear oposición a una ejecución hipotecaria» (ap. 46), no puede decirse otro tanto del momento fijado para iniciar el cómputo del mismo, considerando que, en este aspecto, la disposición cuestionada no resulta respetuosa con el principio de efectividad. Tras observar que «en el Derecho procesal español no es corriente que un plazo procesal comience a correr a partir de la fecha de publicación en el BOE, salvo cuando se trata del recurso inicial contra un acto de alcance general» (ap. 55), sostendría que dicha regulación «no garantiza la plena disponibilidad del plazo, que depende del conocimiento efectivo por los interesados de la existencia de la disposición transitoria cuarta» (ap. 56). Sencillamente, el régimen transitorio adoptado en la Ley 1/2013 genera una notable inseguridad jurídica para los deudores hipotecarios, de tal

30 Asunto aún pendiente de resolución por el TJUE cuando se escriben estas páginas.

31 En el marco del procedimiento de cooperación entre los órganos jurisdiccionales nacionales y el TJUE, puede este último reformular las cuestiones a fin de proporcionar a los primeros una respuesta útil que le permita resolver el litigio. Como recordaría en sus conclusiones el Abogado general: «Para ello, el Tribunal de Justicia puede extraer del conjunto de elementos aportados por el órgano jurisdiccional nacional y, especialmente, de la motivación de la resolución de remisión, las normas y los principios del Derecho de la Unión que requieren una interpretación, teniendo en cuenta el objeto del litigio principal» (apartado 25). 
suerte que los afectados corrían un elevado riesgo de no poder formular oposición a la ejecución; riesgo que «se debe bien a los costes potencialmente disuasorios de la oposición (obligación de contar con un abogado y procurador), bien al desconocimiento de los consumidores acerca de sus derechos, por no tener noticia de la publicación de la Ley 1/2013 y de la disposición transitoria cuarta o, en caso de tenerla, por haber llegado ésta a su conocimiento tardíamente, una vez iniciado el plazo extraordinario» (ap. 59).

Y tras recordar anteriores decisiones del TJUE que declaraban que una situación caracterizada por una gran incertidumbre jurídica puede constituir una vulneración del principio de efectividad (ap. 60), consideró pertinente aplicar al caso la jurisprudencia sobre los plazos razonables. De conformidad con esta línea jurisprudencial, corresponde a los Estados miembros determinar plazos, en relación con las normativas nacionales comprendidas en el ámbito de aplicación del Derecho de la Unión, pero deben tener en cuenta, particularmente, las siguientes circunstancias: la importancia que tengan para los interesados las decisiones que hayan de adoptarse, la complejidad de los procedimientos y de la legislación a aplicar, el número de personas a las que pueden afectar y los demás intereses públicos o privados que deban considerarse (apartados 41 y 61). Y, según la apreciación del abogado general, la valoración de todas y cada una de esas circunstancias conducen a considerar irrazonable la regulación del plazo cuestionada: la notable importancia de las decisiones para los afectados resulta incuestionable, ya que «pueden suponer la pérdida irreversible de sus bienes inmuebles» (ap. 62); es sumamente complejo el marco jurídico delimitado por la articulación de los procedimientos ejecutivo y declarativo y la normativa hipotecaria (ap. 63); el número de afectados es considerable, pues a la entrada en vigor de la Ley 1/2013 eran cientos de miles los procedimientos de ejecución pendientes (ap. 64).

Más concretamente, precisaría el abogado general, «se impone la conclusión de que es precisamente el hecho de que el plazo controvertido en el litigio principal comenzara a correr desde el día siguiente al de la publicación de la Ley $1 / 2013$ lo que excluye que pueda considerarse razonable y de que ese plazo dificultó en exceso el ejercicio efectivo de los derechos conferidos por la Directiva 93/13» (ap. 67) 32 .

Pues bien, es más que probable que estas consideraciones no pasaran inadvertidas al legislador y de ahí que, en el momento de aprobar la conversión del Real Decreto-Ley 11/2014, optara en la Ley 9/2015 por ampliar a dos meses el plazo preclusivo de un mes inicialmente previsto para interponer el recurso de apela-

32 De ahí que más adelante abogara a favor de un plazo que debería notificarse personalmente a los interesados, sugiriendo que «debería subsanarse la falta de notificación a las partes por el mismo expediente que se utiliza en Derecho nacional para notificar a las partes ejecutadas la existencia del procedimiento de ejecución». En suma, «el legislador español debería haber previsto que se notificase a todas las partes demandadas en procedimientos de ejecución la posibilidad de formular un incidente extraordinario de oposición en el plazo de un mes a partir de dicha notificación» (ap. 73). 
ción ${ }^{33}$. Con todo, es cuestionable que esta sola modificación sea suficiente para acomodar la disposición cuestionada a la propuesta de respuesta a la cuestión prejudicial que dio el Abogado general. Pues si la ampliación del plazo parece ajustarse a la misma en el plano formal ${ }^{34}$, es evidente que a lo largo de su argumentación, de forma reiterada, puso de manifiesto que sus objeciones a la regulación del plazo no radicaban en la duración del mismo, sino en la forma en que se reguló su cómputo.

Todo ello sin soslayar las dudas de constitucionalidad que ya había despertado en un sector de la doctrina el régimen transitorio del Real Decreto-Ley 11/2014, por considerar difícilmente compatible con el art. 24.1 CE el hecho de que el inicio del cómputo del plazo para recurrir se conectase directa e inmediatamente con la publicación de la disposición en el $\mathrm{BOE}^{35}$. Desde este punto de vista, en efecto, siendo conocido el domicilio del ejecutado, la sustitución de la notificación personal por la publicación oficial de la norma no parece acomodarse a la consolidada jurisprudencia existente sobre los actos de comunicación procesal, según la cual los órganos judiciales han de apurar las posibilidades de lograr el emplazamiento personal de los afectados a fin de evitar generar situaciones de indefensión (por ejemplo, SSTC 2/2008, FJ 2 y 293/2005, FJ 2); línea jurisprudencial que obviamente resulta de aplicación al procedimiento de ejecución hipotecaria (STC 131/2014).

\section{LA INFLUENCIA DE LA CARTA DE DERECHOS FUNDAMENTALES DE LA UNIÓN EUROPEA EN LA PROTECCIÓN DEL DEUDOR HIPOTECARIO}

Como hemos comprobado líneas arriba, en ocasiones los órganos judiciales, además de la posible inobservancia de la normativa en materia de protección del consumidor, han cuestionado expresamente el respeto del derecho a la tutela judicial efectiva consagrado en el art. 47 de la Carta. Pero incluso en el caso de que falte dicha referencia explícita, parece evidente que no deja de planear la sombra

33 En este sentido, Cordón Moreno, F.: «Después de la Ley 9/2015, de 25 de mayo, subsisten las dudas sobre la conformidad a la Constitución del régimen transitorio aplicable a los recursos en procedimientos de ejecución hipotecaria pendientes», fecha de publicación: 27 de mayo de 2015 (www.uclm.es/centro/ cesco).

34 «A la luz del principio de efectividad, los artículos 6 y 7 de la Directiva 93/13/CEE del Consejo, de 5 de abril de 1993, sobre las cláusulas abusivas en los contratos celebrados con consumidores, se oponen a una disposición nacional transitoria, como la controvertida en el litigio principal, que impone a los consumidores un plazo preclusivo de un mes, a contar desde el día siguiente al de la publicación de la ley de la que forme parte dicha disposición, para formular oposición sobre la base del carácter abusivo de las cláusulas contractuales en el marco de un procedimiento de ejecución hipotecaria en curso» (apartado 74).

35 Cordón Moreno, F.: «Dos cuestiones sobre la reforma del artículo 695.4 de la LEC por el Real Decreto-Ley 11/2014: Su conformidad o no con la doctrina constitucional», Revista CESCO de Derecho de Consumo, n. ${ }^{\circ} 11 / 2014$, pp. 189-190. 
de los derechos fundamentales en las controversias en las que están en juego créditos hipotecarios. La Sentencia $A z i z$ ofrece un buen ejemplo a este respecto.

En el plano formal, lo que se ventiló en la Sentencia $A z i z$ no fue estrictamente sino la interpretación de la Directiva 93/13/EEC, esto es, para decirlo en términos domésticos, una cuestión de «mera» legalidad ordinaria en materia de Derecho de Consumo. Y, sin embargo, por más que en ningún caso se argumentase expresamente en términos del artículo 47 de la Carta, pocas dudas cabía albergar acerca de que la Sentencia entrañaba, materialmente, una mejora en la protección del derecho a la tutela judicial efectiva en relación con la vivienda y, en consecuencia, que, siquiera de forma indirecta, proporcionaba un más alto estándar de protección de derechos fundamentales que el estándar constitucional nacional ${ }^{36}$. Al fin y al cabo, el principio de efectividad como límite de la autonomía procesal de los Estados miembros — que articuló la argumentación en $A z i z$ - en buena medida se proyecta y cristaliza en el derecho garantizado en el art. 47 de la Car$\mathrm{ta}^{37}$. Disposición ésta que no sería sino una muestra de lo que se ha dado en definir como el proceso de «constitucionalización del Derecho Privado de la Unión Europea», entendiendo por tal la experiencia de elevar a nivel constitucional ciertos principios preexistentes, como habría sucedido en este caso con la transformación en derecho fundamental del principio de protección jurídica efectiva ${ }^{38}$.

Por lo demás, no resulta necesario insistir en que, en aquellos supuestos en que el TJUE aprecia junto a la inobservancia de la Directiva una vulneración de un derecho consagrado en la Carta, la Sentencia adquiere una especial dimensión y un singular alcance, dada la importante función que, en el marco del art. 10.2 CE, está llamado a desempeñar el TJUE a raíz del Tratado de Lisboa ${ }^{39}$. Pues, desde su entrada en vigor, la Carta de Derechos Fundamentales de la Unión Europea se ha convertido en un nuevo término de referencia para delimitar el alcance de nuestros derechos fundamentales y, en consecuencia, el Tribunal de Justicia

36 En este sentido, véase el excelente comentario de IGLESIAS SÁNCHEZ, SARA: «Unfair terms in mortgage loans and protection of housing in times of economic crisis: Aziz v. Catalunyacaixa», Common Market Law Review 51, 2014, pp. 956 y 970-971.

37 Sobre la conexión material existente entre la doctrina del principio de efectividad y el derecho fundamental a la tutela judicial efectiva, véanse, por ejemplo, LóPEz Escudero, MANUEL: «Artículo 47. Derecho a la tutela judicial efectiva y a un juez imparcial», en MANGas Martín, Araceli: Carta de los Derechos Fundamentales de la Unión Europea, Fundación BBVA, Bilbao, 2008, pp. 743-748; MAK, ChAnTAL: Rights and Remedies. Article 47 EUCFR and Effective Judicial Protection in European Private Law Matters Centre for the Study of European Contract Law Working Paper n. ${ }^{\circ}$ 2012-11 (https://ssrn.com/abstract=2126551).

38 Micklitz, Hans-W.: «The ECJ Between the Individual Citizen and the Member States - A Plea for a Judge-Made European Law for Remedies», Micklitz, Hans-W./DE WitTe, Bruno (eds.): The European Court of Justice and the Autonomy of the Member States, Antworp: Intersentia, Cambridge, 2012, pp. 362-363.

39 La incorporación de la Carta de los Derechos Fundamentales al Derecho europeo primario vino a disipar la incertidumbre — más que fundada - existente con anterioridad acerca de si la jurisprudencia europea en materia de derechos era una referencia obligada para interpretar nuestros propios derechos fundamentales en virtud del art. 10.2 CE (véase Arzoz Santisteban, X.: «La relevancia del Derecho de la Unión Europea para la interpretación de los derechos fundamentales constitucionales», REDC, $\mathrm{n} .^{\circ} 74$, 2005, p. 63 y ss.). 
pasa a ser, siquiera indirectamente, al igual que el Tribunal de Estrasburgo, un intérprete autorizado de los derechos consagrados en la Constitución ${ }^{40}$. Los términos de sus Sentencias vendrán a delimitar el propio derecho constitucional en juego y, por tanto, seguirán vinculando a nuestros operadores jurídicos con independencia de las vicisitudes por las que atraviese en el futuro la Directiva cuya inobservancia generó la controversia.

Pero la posible incidencia de la Carta en los casos relativos a deudores hipotecarios no se agota con el derecho contenido en su artículo 47. Cabría asimismo especular con el papel que puede jugar en estos asuntos la «vivienda», en cuanto bien expresamente protegido en la Carta. Protección de la vivienda familiar que, como ya apuntamos, hizo acto de presencia en la Sentencia Aziz (apartado 61), siquiera como punto de vista, consideración o criterio para reforzar la decisión del TJUE. En línea de principio, sin embargo, es reducida la tutela que la Carta brinda explícitamente al respecto, pues sólo reconoce el «derecho a una ayuda de vivienda para garantizar una existencia digna a todos aquellos que no dispongan de recursos suficientes, según las modalidades establecidas por el Derecho de la Unión y por las legislaciones y prácticas nacionales» (art. 34.3); una disposición que, con independencia de su limitado ámbito material, claramente consagra un «principio»y no un genuino «derecho» en el sentido de lo establecido en el art. 52 de la Carta $^{41}$.

Naturalmente, este escenario cambia sustancialmente si — como se ha sugerido $^{42}$ - se entiende que la protección de la vivienda habitual deriva de un verdadero «derecho», cual es el contenido en el art. 7 de la Carta ${ }^{43}$. Desde esta perspectiva, los litigios entre acreedores y deudores hipotecarios se presentarían como casos de colisión o conflicto entre derechos fundamentales reconocidos en la Carta: frente a la libertad de empresa de la entidad financiera (art. 16) se opondría el derecho a la vivienda habitual del consumidor (ex art. 7). Y, de acuerdo con la Sentencia Promusicae ${ }^{44}$, en estos supuestos, sobre los legisladores nacionales pende la obligación de llegar a una adecuada ponderación de los derechos en liza: «... corresponde a los Estados miembros, a la hora de adaptar a su ordenamiento ju-

40 Requejo Pagés, J. L.: «Doctrina del Tribunal Constitucional durante el segundo cuatrimestre de 2011», Revista Española de Derecho Constitucional, n. ${ }^{\circ}$ 93, 2011, p. 259. Autor que destaca la circunstancia de que la LO 1/2008 no se limitase a autorizar la ratificación del Tratado de Lisboa en su artículo 1, sino que además reprodujese en su integridad la Carta (art. 2) para ratificar la plena operatividad del mandato hermenéutico del art. 10.2 CE.

41 Sobre la distinción entre las categorías de «derecho» y «principio» bastará con remitirse a las Conclusiones del Abogado general Pedro Cruz Villalón, presentadas el 18 de julio de 2013, en el Asunto C-176/12 (Association de médiation sociale), apartados 43-79.

42 Cherednychenko, Olha O.: «Fundamental Rights, European Private Law, and Financial Services», Micklitz, Hans-W. (ed.): Constitutionalization of European Private Law, Oxford University Press, 2014, pp. 197-199.

43 «Toda persona tiene derecho al respeto de su vida privada y familiar, de su domicilio y de sus comunicaciones».

44 Sentencia del Tribunal de Justicia (Gran Sala), de 29 de enero de 2008 (asunto C-275/06). 
rídico a las Directivas... procurar basarse en una interpretación de éstas que garantice un justo equilibrio entre los distintos derechos fundamentales protegidos por el ordenamiento jurídico comunitario» (apartado 68).

Aunque a mi juicio es más que dudoso que el ámbito protegido por el derecho ex art. 7 de la Carta llegue tan lejos, conviene dejar constancia de que esta lectura expansiva del precepto parece estar abriéndose paso, siquiera tímida y calladamente, en el seno del TJUE. Ésta es la conclusión que cabe inferir del Auto del Tribunal de Justicia (Sala Primera) de 16 de julio de 2015, que vino a resolver la petición de decisión prejudicial planteada por la Audiencia Provincial de Castellón mediante resolución de 21 de noviembre de 2014 (asunto C-539/14). Petición que se produjo en el marco del mismo litigio entre los Sres. Sánchez Morcillo y Abril García y el Banco Bilbao Vizcaya que dio origen a la STJUE de 17 de julio de 2014 (asunto C-169/14), pero en esta ocasión lo que cuestiona el órgano judicial es la adecuación de la modificación del art. 695.4 LEC efectuada por el Real Decreto-Ley 11/2014 a la normativa europea. Y a diferencia de lo sucedido en el asunto C-169/14, la Audiencia Provincial de Castellón no sólo plantea la interpretación del art. 7.1 de la Directiva 93/13 en relación con el art. 47 de la Carta, sino también en conexión con sus arts. 34.3 y 7 .

Pues bien, en lo concerniente a la interpretación de la Directiva en relación con el art. 34.3 de la Carta, el TJUE fue concluyente al declarar que no resultaba necesario pronunciarse sobre la misma: «En efecto, dado que, en contra de lo señalado por ese órgano jurisdiccional, esa disposición de la Carta no garantiza el derecho a la vivienda sino el 'derecho a una ayuda social y a una ayuda de vivienda' en el marco de las políticas sociales basadas en el artículo 153 TFUE, tal interpretación no es pertinente de cara a la resolución del litigio principal» (apartado 49). Por el contrario, no duda en extender su pronunciamiento al «derecho al respeto de la vida privada y familiar y del domicilio» (art. 7) con la misma naturalidad que lo hace al principio de igualdad de armas integrante del derecho a la tutela judicial efectiva del art. 47 de la Carta (apartado 46). Y en aplicación de los criterios jurisprudenciales apuntados en la STJUE de 17 de julio de 2014, la respuesta a la cuestión planteada fue que «el artículo 7 , apartado 1, de la Directiva 93/13, en relación con los artículos 7 y 47 de la Carta, debe interpretarse en el sentido de que no se opone» al reformado art. 695.4 LEC (apartado 50).

Parece evidente que, de consolidarse esta tendencia apuntada en el Auto de 16 de julio de 2015, se ampliaría sustancialmente la posibilidad de presentar ante el TJUE como un caso de derechos fundamentales cualquier controversia hipotecaria en la que esté en juego la vivienda habitual.

$* * *$

TITLE: Right to housing and evictions: the protection of the mortgage debtor in the EUCJ's case-law

ABSTRACT: In the last years, the issue of mortgage enforcement proceedings in Spain bas been the subject of an extensive debate drawing attention to the deficiencies of such procedure in a situation of severe crisis like the 
one Spanish households were experiencing. Particularly, it was highly criticized because there has been traditionally quite restricted possibilities of opposition for the defendant. However, the system of mortgage enforcement, including the limitation of grounds of objection, had been repeatedly declared in conformity with the Constitution by the Constitutional Court. In this context, the role of the Court of Justice of the EU has been crucially important in fine-tuning the national legal provisions in light of the European legal instruments (Directive 93/13) EEC on unfair terms in consumer contracts). Nonetheless, the fact that the solution found in EU law emanates from the sphere of consumer protection law should not overshadow the fact that the principle of effectiveness is the main element at the basis of the reasoning of the Court, which in an expression of the principle of effective judicial protection enshrined in Article 47 of the Charter of Fundamental Rights of the European Union.

RESUMEN: En los últimos años ha sido objeto de un amplio debate la configuración del procedimiento de ejecución hipotecaria, en el que se ha puesto el acento en sus deficiencias en una situación de crisis tan profunda como la que estaban padeciendo las familias en España. Especialmente, recibió severas críticas porque tradicionalmente ha restringido las posibilidades que tiene el deudor de oponerse a la ejecución. Y sin embargo, el Tribunal Constitucional, en repetidas ocasiones, habia declarado la constitucionalidad del sistema procesal bipotecario, incluyendo la limitación de los motivos de oposición. En este contexto, el papel del TJUE ha sido determinante para que se procediera a la modificación del marco normativo interno al objeto de acomodarlo al derecho europeo (Directiva 93/137/CEE sobre las cláusulas abusivas en los contratos celebrados con consumidores). Con todo, la circunstancia de que la solución proviniera del derecho europeo en materia de protección de consumidores no debe eclipsar la circunstancia de que el principio de eficacia, que constituye el eje central de la argumentación del TJUE, no es sino expresión del derecho a la tutela judicial efectiva consagrado en el art. 47 de la Carta de Derechos Fundamentales de la Unión Europea.

KEY WORDS: Charter of Fundamental Rights of the European Union, right to an effective remedy, right to housing, mortgage enforcement proceedings, unfair terms.

Palabras Clave: Carta de Derechos Fundamentales de la Unión Europea, derecho a la tutela judicial efectiva, derecho a la vivienda, procedimiento de ejecución hipotecaria, cláusulas abusivas.

FECHA DE RECEPCIÓN: 25.09.2015 FECHA DE ACEPTACIÓN: 30.09.2015 